
F. Staub
C. Tournoux-Facon
J. Roumy
C. Chaigneau
M. Morichaut-Beauchant
P. Levillain
C. Prevost
C. Aubé
J. Lebigot
F. Oberti
J. B. Galtier
H. Laumonier
H. Trillaud
P. H. Bernard
J. F. Blanc
S. Sironneau
F. Machet
J. Drouillard
V. de Ledinghen
P. Couzigou
P. Foucher
L. Castéra
F. Tranquard
Y. Bacq
L. d'Altéroche
P. Ingrand
J. P. Tasu

Published online: 6 June 2009

(C) European Society of Radiology 2009

\author{
The online version of the original article can be \\ found at http://dx.doi.org/10.1007/s00330 \\ 009-1313-x \\ F. Staub · J. Roumy $\cdot$ C. Prevost . \\ J. P. Tasu \\ Department of Radiology, \\ CHU de Poitiers, \\ 2 rue de la Milétrie, \\ 86000 Poitiers, France \\ C. Chaigneau • \\ M. Morichaut-Beauchant \\ Department of Hepatology, \\ CHU de Poitiers, \\ 2 rue de la Milétrie, \\ 86000 Poitiers, France

\section{P. Levillain} \\ Department of Pathology, \\ CHU de Poitiers, \\ 2 rue de la Milétrie, \\ 86000 Poitiers, France
}

\title{
Liver fibrosis staging with contrast-enhanced
ultrasonography: prospective multicenter study \\ Liver fibrosis staging with contrast-enhanced
ultrasonography: prospective multicenter study compared with METAVIR scoring
}

C. Tournoux-Facon · P. Levillain ·

P. Ingrand

Centre d'investigation clinique

INSERM CIC-P U802,

CHU de Poitiers,

2 rue de la Milétrie,

86000 Poitiers, France

C. Aubé · J. Lebigot

Radiology Department, CHU d'Angers,

Angers, France

F. Tranquard

Radiology Department, CHU de Tours,

Tours, France

J. B. Galtier · H. Laumonier •

H. Trillaud - S. Sironneau - F. Machet ·

J. Drouillard

Radiology Departement,

CHU de Bordeaux,

Bordeaux, France

\section{F. Oberti}

Hepatology Department, CHU d'Angers,

Angers, France

P. H. Bernard · J. F. Blanc

V. de Ledinghen $\cdot$ P. Couzigou ·

P. Foucher - L. Castéra

Hepatology Department,

CHU de Bordeaux,

Bordeaux, France

Y. Bacq · L. d'Altéroche

Hepatology Department,

CHU de Tours,

Tours, France

F. Staub $(\square)$

Fabrice Staub service de Radiologie,

2 rue de la Milétrie,

86000 Poitiers, France

e-mail: fabricestaub@hotmail.com

Tel.: +33-5-49444311

Fax: +33-5-49444261 


\section{Eur Radiol (DOI 10.1007/s00330-009-1313-x)}

The affiliation of some authors are wrong. Please find the correct ones below:

M. Morichau-Beauchant ${ }^{2}$ P. Levillain ${ }^{3}$.

In the paragraph Statistical Analysis, "interclass correlation coefficients" (line 1) should be replaced by "intraclass correlation coefficients" or "Kappa coefficients".

In the paragraph Results, "the interclass correlation" (line 8) should be replaced by "the Kappa coefficients" and in the sentence beginning by "for calculating the transit time..." (line 9), "correlation" should be replaced by "concordance" and "Kappa" should be replaced by "intraclass correlation coefficient".

In the ROC curve of Fig. 4, sensitivity and specificity should be reversed. See corrected figure below.

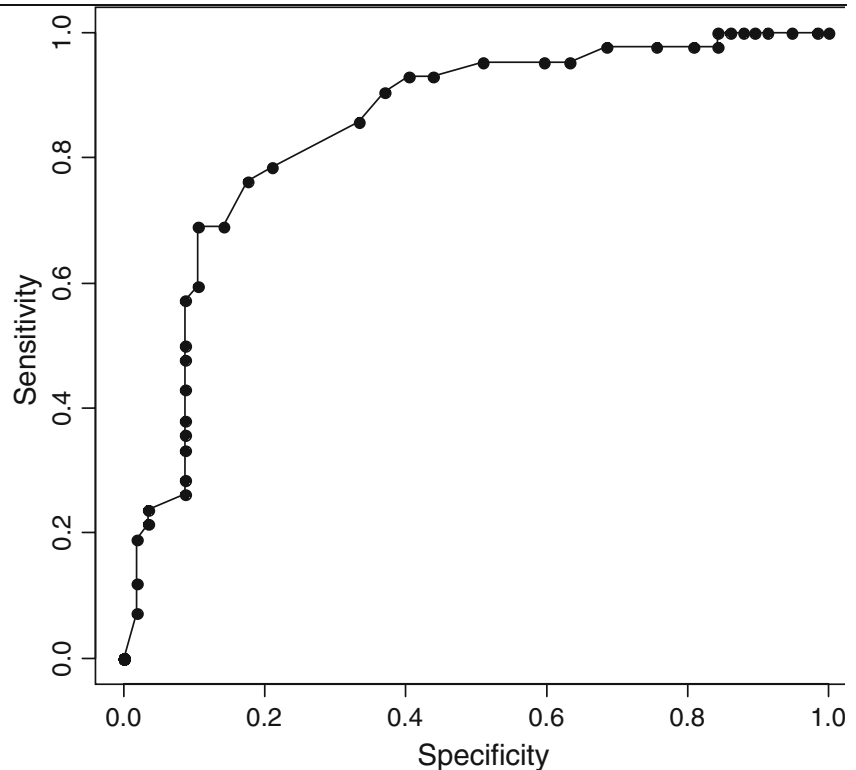

Fig. 4 Receiver operating characteristic (ROC) curve for the diagnosis of severe fibrosis: area under the curve estimated at 0.847 (95\% CI: $0.768-0.926)$ 